\title{
Fast Kinetics, High-Frequency Oscillations, and Subprimary Firing Range in Adult Mouse Spinal Motoneurons
}

\author{
Marin Manuel, ${ }^{1,2}$ Caroline Iglesias, ${ }^{1}$ Maud Donnet, ${ }^{1}$ Félix Leroy, ${ }^{1}$ C. J. Heckman, ${ }^{2,3}$ and Daniel Zytnicki ${ }^{1}$ \\ ${ }^{1}$ Laboratoire de Neurophysique et Physiologie (Centre National pour la Recherche Scientifique, Unité Mixte de Recherche 8119), Université Paris Descartes, \\ Paris 75006, France, and Departments of ${ }^{2}$ Physiology and ${ }^{3}$ Physical Medicine and Rehabilitation, Northwestern University Feinberg School of Medicine, \\ Chicago, Illinois 60611
}

The fast contraction time of mouse motor units creates a unique situation in which motoneurons have to fire at low frequencies to produce small forces but also at very high frequency (much higher than in cat or rat motoneurons) to reach the fusion frequency of their motor units. To understand how this problem is solved, we performed intracellular recordings of adult mouse spinal motoneurons and investigated systematically their subthreshold properties and their discharge pattern. We show that mouse motoneurons have a much wider range of firing frequencies than cat and rat motoneurons because of three salient features. First, they have a short membrane time constant. This results in a higher cutoff frequency and a higher resonance frequency, which allow mouse motoneurons to integrate inputs at higher frequencies. Second, their afterhyperpolarization (AHP) is faster, allowing the motoneurons to discharge at a higher rate. Third, motoneurons display high-frequency $(100-150 \mathrm{~Hz})$ subthreshold oscillations during the interspike intervals. The fast membrane kinetics greatly favors the appearance of these oscillations, creating a "subprimary range" of firing. In this range, which has never been reported in cat and in rat spinal motoneurons, the oscillations follow the AHP and trigger spiking after a variable delay, allowing a discharge at low frequency but at the expense of an irregular rate.

\section{Introduction}

Murine models of human degenerative diseases of motoneurons, such as amyotrophic lateral sclerosis or spinal muscular atrophy, have been available for some years (Gurney et al., 1994; Frugier et al., 2000; Hsieh-Li et al., 2000; Monani et al., 2000). To decipher the pathophysiological mechanisms leading to degeneration, it is crucial to investigate the electrophysiological properties of the motoneurons. As yet, electrophysiological studies have only been performed in embryonic cultures of motoneurons and in isolated lumbar cords of neonatal animals (Kuo et al., 2005; Bories et al., 2007; van Zundert et al., 2008). However, electrophysiological investigations in older animals, at the onset of symptoms and during the course of the disease, can only be performed in vivo.

Very few intracellular recordings of motoneurons have been made in adult anesthetized mice (Huizar et al., 1975; Alstermark and Ogawa, 2004; Meehan et al., 2008). Despite these studies, the intrinsic properties of adult mouse motoneurons remain primarily unknown because of the difficulty in obtaining stable record-

Received July 7, 2009; revised July 30, 2009; accepted Aug. 3, 2009.

This work was supported by the Centre National pour la Recherche Scientifique (CNRS), the Association Française contre les Myopathies (MNM2 2009, Grant 14229), and the National Institutes of Health-National Institute of Neurological Disorders and Stroke (Grant NS05462). M.M. was supported by the Fondation pour la Recherche Médicale and the Milton Safenowitz Post Doctoral Fellowship for ALS Research (ALS Association). C.I. was supported by a postdoctoral fellowship from the CNRS. We thank Dr. C. Meunier for helpful discussions and comments on this manuscript. We are also indebted to Dr. D. Dubayle for help with the fluorescent microscopy, to A. Goulian for taking care of animals, and to $\mathrm{H}$. Suaudeau for script programming.

Correspondence should be addressed to Marin Manuel, Department of Physiology, Northwestern University Feinberg School of Medicine, 303 East Chicago Avenue, Chicago, IL 60611. E-mail: marin.manuel@ northwestern.edu.

DOI:10.1523/JNEUROSCI.3260-09.2009

Copyright $\odot 2009$ Society for Neuroscience $\quad$ 0270-6474/09/2911246-11\$15.00/0 ings. In the present study, we have developed a preparation that allows us to make stable intracellular recordings in lumbar motoneurons of adult anesthetized mice. As a first step, we systematically investigated the subthreshold and the discharge properties of mature mouse motoneurons in wild-type mice.

We studied the properties that allow mouse motoneurons to drive motor units that are contracting faster than in rats or cats (Lewis et al., 1982; Bateson and Parry, 1983). This short contraction time creates a unique situation in which mouse motoneurons have to discharge at a high rate to reach the tetanus fusion frequency of their motor units, but still need to be able to fire at low frequencies to produce small forces. In other words, mouse motoneurons require a wide firing range. Mouse motoneurons solve this problem using three striking features. First, they have a shorter membrane time constant than cat and rat motoneurons. This results in a higher cutoff frequency and a higher resonance frequency, allowing mouse motoneurons to integrate inputs at higher frequencies. Second, their afterhyperpolarization (AHP) is faster, allowing the motoneurons to discharge at a higher rate. Third, motoneurons display high-frequency $(100-150 \mathrm{~Hz})$ subthreshold oscillations during the interspike intervals. The fast membrane kinetics greatly favors the appearance of these oscillations that create a "subprimary range" of firing. In this range, which has never been reported in cat and in rat spinal motoneurons, the oscillations follow the AHP and trigger spiking after a variable delay, allowing a discharge at low frequency but at the expense of an irregular rate.

\section{Materials and Methods}

Animal preparation. Experiments were performed on 20 adult mice weighing 20-42 g (strains used were OF1, CD1, C57SJL, and C57BL/6, 
$A_{1}$

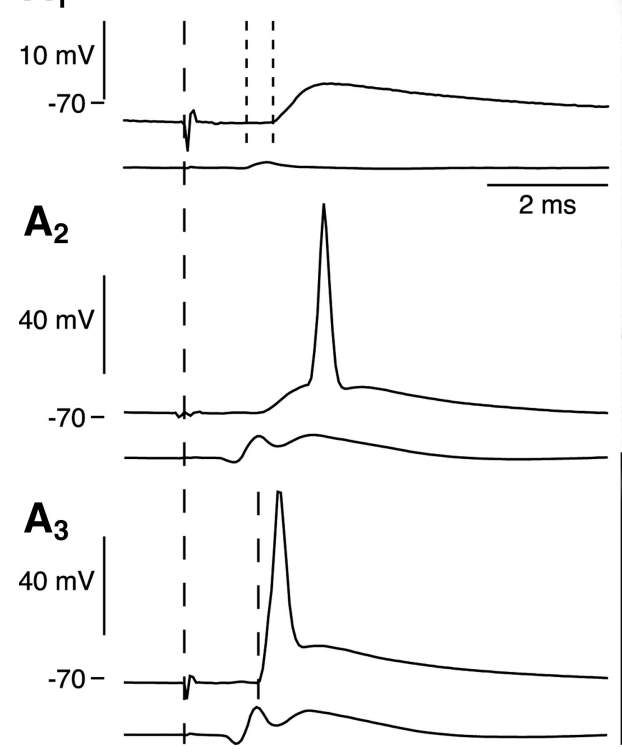

$B_{1}$

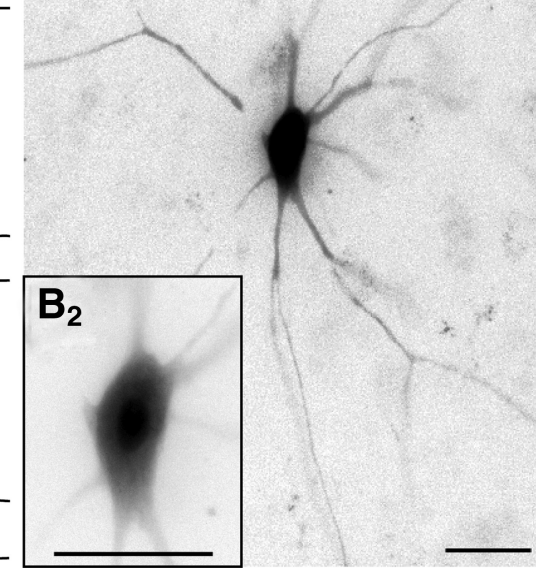

Figure 1. Motoneuron identification. $\boldsymbol{A}$, Response of a motoneuron to an increasing electrical stimulation of the sciatic nerve. The vertical dashed line indicates the time of the stimulation. Each panel is the intracellularly recorded membrane potential (top trace) and the afferent volley recorded on the surface of the lumbar cord (bottom trace). $\boldsymbol{A}_{1}$, At an intensity just above threshold for recruitment of group I afferents $(1.1 \times \mathrm{T})$, an EPSP appeared in response to the electrical stimulation. The EPSP was monosynaptic because its central latency, $0.4 \mathrm{~ms}$ (small vertical dotted lines), was too short for a pathway involving more than one synapse. Traces are an average of eight sweeps. $\boldsymbol{A}_{2}$, Increasing the stimulation intensity $(2.0 \times \mathrm{T})$ increased the size of the EPSP until it was large enough to trigger an orthodromic spike. Traces are an average of nine sweeps. Notice that the stimulation artifact appears smaller because of some jitter in the spike time, which has been used as reference to average the traces. $A_{3}$, When the stimulation intensity was increased even more $(2.1 \times \mathrm{T})$, the axon was recruited, and an antidromic action potential appeared with a $1.2 \mathrm{~ms}$ latency with respect to the stimulation time. Given a conduction length of $38 \mathrm{~mm}$, the axonal conduction velocity was $32 \mathrm{~m} / \mathrm{s}$. Traces are an average of six sweeps. $\boldsymbol{B}_{\boldsymbol{1}}$, Intracellular labeling of the same motoneuron with tetramethylrhodamine dextran (2\%; $3000 \mathrm{MW}$; Invitrogen) in the recording microelectrode. After the recording session, the dye was injected into the neuron with a continuous depolarizing current (total $27 \mathrm{nA} \cdot \mathrm{min}$ ). Forty-five minutes later, the mouse was perfused intracardially with $40 \mathrm{ml}$ of PBS and then $200 \mathrm{ml}$ of a solution of 4\% paraformaldehyde in PBS. After an overnight immersion in a solution of $30 \%$ sucrose in PBS at $4^{\circ} \mathrm{C}$, the spinal cord was cut into $120 \mu \mathrm{m}$ sections and mounted in Vectashield (Vector Laboratories). Observation was done using a fluorescence microscope (BX61; 0lympus) at low magnification (20× objective) and a cooled video camera (Retiga 2000R; Qimaging) with a color conversion filter. $\boldsymbol{B}_{2}$, Soma of the same motoneuron at higher magnification ( $60 \times$ objective). Calibration, $50 \mu \mathrm{m}$ in both images.

either from Charles River Laboratories France or bred at Northwestern University). The same protocol was used in experiments in Paris and in Chicago. They yielded the same results, and the data were pooled together. In accordance with French legislation, the investigators had valid licenses to perform experiments on live vertebrates delivered by the Direction des Services Vétérinaires (Préfecture de Police, Paris). Experiments conducted at Northwestern University were performed under full approval from the Northwestern University Animal Care and Use Committee. At the onset of experiment, atropine $(0.20 \mathrm{mg} / \mathrm{kg}$; Aguettant $)$ and methylprenidsolone ( $0.05 \mathrm{mg}$; Solu-Medrol; Pfizer) were given subcutaneously to prevent salivation and edema, respectively. Fifteen minutes later, the anesthesia was induced with an intraperitoneal injection of sodium pentobarbitone ( $70 \mathrm{mg} / \mathrm{kg}$; Pentobarbital; sanofi-aventis). A tracheotomy was performed, and the mouse was artificially ventilated with pure oxygen (SAR-830/P ventilator; CWE). The end tidal $\mathrm{PCO}_{2}$ was maintained around 4\% (MicroCapstar; $\mathrm{CWE}$ ). The heart rate was monitored (CT-1000; CWE), and the central temperature was kept at $38^{\circ} \mathrm{C}$ using an infrared heating lamp. A catheter was introduced in the external jugular vein, allowing us to supplement the anesthesia whenever necessary (usually every $10-20 \mathrm{~min}$ ) by intravenous injections $(6 \mathrm{mg} / \mathrm{kg})$. The adequacy of anesthesia was assessed on lack of noxious reflexes and on the stability of the heart rate (usually $400-500 \mathrm{bpm}$ ) and end-tidal $\mathrm{PCO}_{2}$. A slow intravenous infusion $(50 \mu \mathrm{l} / \mathrm{h})$ of a $4 \%$ glucose solution containing $\mathrm{NaHCO}_{3}(1 \%)$ and gelatin (14\%; Plasmagel; Roger Bellon) helped to maintain the physiological parameters. The sciatic nerve was dissected and mounted on a monopolar electrode for stimulation. The vertebral column was immobilized with two pairs of horizontal bars (Cunningham Spinal Adaptor; Stoelting) applied on the Th12 and L2 vertebral bodies, and the L3-L4 spinal segments were exposed by a laminectomy at the Th13-L1 level. The tissues in hindlimb and the spinal cord were covered with pools of mineral oil. After the surgery, the animal was paralyzed with pancuronium bromide (Pavulon; Organon; initial bolus was $0.1 \mathrm{mg}$, followed by a continuous infusion $0.01 \mathrm{mg} / \mathrm{h}$ ). This preparation allowed us to keep the animal for $6-10 \mathrm{~h}$ after the end of the surgery and to make stable intracellular recordings of motoneurons. At the end of the experiments, animals were killed with a lethal intravenous injection of pentobarbitone.

Recordings. Intracellular recordings of motoneurons were done using micropipettes (tip diameter, $1.0-1.5 \mu \mathrm{m}$ ) filled either with $3 \mathrm{M}$ $\mathrm{KCl}$ (resistance, 5-10 $\mathrm{M} \Omega$ ) or, in two experiments, with $2 \mathrm{M}$ potassium acetate (resistance, 10-18 M $\Omega$ ). The results were the same with both types of electrodes. Recordings were made using the Axoclamp 2B amplifier (Molecular Devices) connected to a Power1401 interface and using the Spike2 software (CED). After impalement, identification of motoneurons rested on the observation of antidromic action potentials in response to the electrical stimulation of their axon in the sciatic nerve as shown in Figure $1 A_{1}-A_{3}$. As in cats, the recruitment threshold for motor axons was higher than the recruitment threshold of Ia afferents, and the antidromic action potential abolished the orthodromic one because of the refractoriness that followed the antidromic spike. However, the antidromic action potential was blocked in some motoneurons. In these cases, motoneurons were identified on the observation of a monosynaptic EPSP, or an orthodromic action potential, and on the fact they were located in the vicinity (same depth) of identified motoneurons.

All motoneurons retained for analysis had a resting membrane potential more hyperpolarized than $-50 \mathrm{mV}$ and an overshooting action potential $>65 \mathrm{mV}$. Low resting membrane potentials coupled with large spike amplitudes indicated that the microelectrode impalements did not elicit a large somatic shunt. No leakage of the dye was observed out of the soma in motoneurons labeled intracellularly after the recording (Fig. $1 B$ ).

All recordings (except for the membrane time constant measurement, which was done in Bridge mode) were performed using the Discontinuous Current Clamp mode (7-9 kHz) of the amplifier because it allows for reliable measurements of the membrane potential, even when large currents are injected (Brizzi et al., 2004).

Subthreshold properties. A series of small-amplitude ( -3 to $+3 \mathrm{nA})$, $500 \mathrm{~ms}$ square current pulses were used to plot the $I-V$ relationship. As mouse motoneurons display a sag (see Fig. $2 B$ ), measurements were made both at the peak and the plateau of the voltage responses, yielding two $I-V$ curves. The peak $\left(R_{\text {peak }}\right)$ and the plateau input resistances $\left(R_{\text {plateau }}\right)$ were estimated by the slope of the linear regressions in the -1.5 to $+1.5 \mathrm{nA}$ range. This portion of the $I-V$ curves was always linear. The "sag ratio" of the voltage response was then computed as the ratio of the peak resistance over the plateau resistance (Manuel et al., 2005).

The membrane time constant was measured using the relaxation of the potential after the injection of small hyperpolarizing current pulses $(-5 \mathrm{nA}, 1 \mathrm{~ms})$. The membrane time constant $\left(\tau_{\mathrm{m}}\right)$ was obtained by fitting a straight line to the linear portion of the logarithm of the voltage. 
The absolute value of the slope of this linear region gave the membrane time constant. The first equalizing time constant $\left(\tau_{1}\right)$ was then obtained by "peeling off" the membrane time constant and doing a second linear fit.

Assuming that the motoneuron (soma and dendrites) can be approximated by an equivalent cylinder with spatially uniform membrane resistivity and capacitance, the electrotonic length was derived from the membrane time constant and the first equalizing time constant according to $L=\pi / \sqrt{ }\left(\tau_{\mathrm{m}} / \tau_{1}-1\right)$, and the total capacitance of the motoneuron was estimated from the equation $C=\left(\tau_{\mathrm{m}} \times L\right) /\left(R_{\text {peak }} \times\right.$ $\tanh (L)$ ) (Rall, 1969; Gustafsson and Pinter, 1984; Rall et al., 1992). Since the estimates of $L$ and $C$ are obtained in the same way as in previous works on cat and rat motoneurons (Gustafsson and Pinter, 1984; Cormery et al., 2005), we can readily compare the properties of mouse motoneurons with those reported for cats and rats.

We used the impedance amplitude profile (ZAP) method to characterize the resonant behavior of the cells as fully described by Manuel et al. (2007). We generated a sine wave current, $I_{Z A P}(t)=a \times \sin \left(b \times t^{k}\right)$, of 10-30 s duration with the Power1401. The amplitude $a$ was set to $0.5-1.5 \mathrm{nA}$. The frequency, which is the derivative of the phase $b \times t^{k}$, increased as $t^{2}(k=$ 3) from 0 to $100 \mathrm{~Hz}$. We recorded 3-10 voltage responses, which were averaged off-line, and calculated the impedance $Z$ as the ratio of the fast Fourier transforms of the voltage response and of the ZAP current. The frequency response curve (FRC) was obtained by plotting the impedance modulus versus the frequency. This curve was smoothed using a running average with a window of $3-5 \mathrm{~Hz}$. A resonance of the neuron corresponded to a peak of the FRC at a preferred frequency (Hutcheon and Yarom, 2000). The acuity of the resonance was quantified by the quality factor $Q$, defined as the ratio of the frequency response at the resonance frequency to the response at low frequency $(1 \mathrm{~Hz}$, in our case).

Action potential properties. The characteristics of action potentials were measured on spikes elicited by short intracellular depolarizing pulses. This ensured that the AHP was not contaminated by a substantial recurrent inhibition and by postsynaptic actions from afferents when stimulating the sciatic nerve. Single action potentials were elicited by brief depolarizing pulses of current $(5 \mathrm{nA}, 0.5 \mathrm{~ms})$ repeated at the frequency of $2 \mathrm{~Hz}$. We averaged $\sim 20$ successive records. We measured the spike height and its width at half-amplitude. We also measured the AHP amplitude, half-decay time (i.e., time between the AHP trough and the point where the AHP relaxed to half its amplitude), time constant (by fitting an exponential curve to the tail of the AHP), and total duration (i.e., the time between the beginning of the AHP and the point at which it had repolarized by 99\%).

Discharge properties. The discharge properties were investigated using triangular ramps of current of slow velocity $(0.1-2.5 \mathrm{nA} / \mathrm{s})$ and with a maximum intensity of 3-16 nA, depending on the recruitment threshold of the motoneuron. F-I curves were obtained by plotting the instantaneous firing frequency versus the intensity of the injected current at the time of the spike. In few cases, long-lasting (500 ms) depolarizing current pulses, repeated at the frequency of $1 \mathrm{~Hz}$, were also used to study the stationary discharge properties and firing frequency adaptation. The mean firing frequency was measured on the last $350 \mathrm{~ms}$ (to discard the initial frequency adaptation phase), averaged over at least three pulses, and plotted against the intensity of the current pulse to obtain the stationary F-I curve.

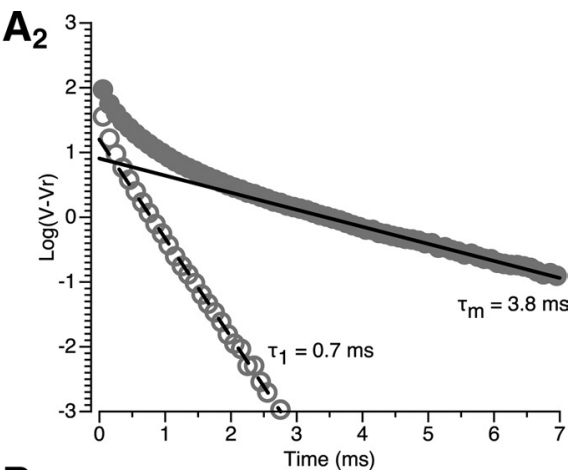

$\mathbf{B}_{2}$

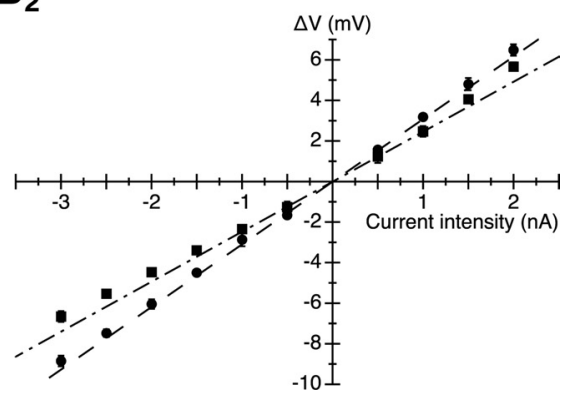

$250 \mathrm{~ms}$

. Subthreshold properties of a typical mouse motoneuron. $A$, Measurement of the membrane time constant. $A_{y}$ (bottom traces) lasting $500 \mathrm{~ms}$ and ranging from -3 to +2 nA. Notice the sag on the voltage respons been measured at the end of the pulse, as depicted by the symbols on top of $\boldsymbol{B}_{1}$. Straight lines are the best linear fits of the peak response (dashed) and the plateau response (dashed-dotted). The slopes of these lines are the peak input resistance and the plateau input resistance of the motoneuron, respectively.

\section{Results}

We report here the properties of 37 mouse lumbar motoneurons.

\section{Mouse motoneurons have a faster membrane time constant than cat and rat motoneurons despite their higher input resistance}

We found that the membrane time constant of the mouse lumbar motoneurons is briefer than in cat and rat motoneurons. Figure $2 A_{1}$ shows a motoneuron with one of the largest time constants. A clear linear zone appeared on the semilogarithmic plot of the voltage (Fig. $2 \mathrm{~A}_{2}$, filled dot curve). The membrane time constant was $3.8 \mathrm{~ms}$ in the illustrated case. In our sample, the membrane time constants ranged from 0.5 to $4 \mathrm{~ms}$ (mean $2.5 \pm 1.0 \mathrm{~ms} ; n=$ 35) (Fig. 3A). For comparison, the membrane time constant of lumbar motoneurons is two to three times larger in cats (Table 1) (Gustafsson and Pinter, 1984; Zengel et al., 1985) and approximately one-and-a-half to two times larger in rats (Beaumont and Gardiner, 2002; Cormery et al., 2005).

In most cases, a voltage sag appeared in the responses to both depolarizing and hyperpolarizing pulses (Fig. $2 B_{1}$, filled arrowhead), and a rebound (either hyperpolarizing or depolarizing) (Fig. $2 B_{1}$, open arrowhead) was visible after the cessation of the pulse. The sag and the rebound increased with the size of the pulses. This suggested the presence of an $I_{h}$ current (McLarnon, 1995; Pape, 1996). In the illustrated motoneuron, the peak and the plateau input resistances were equal to 3.0 and $2.3 \mathrm{M} \Omega$, re- 
A
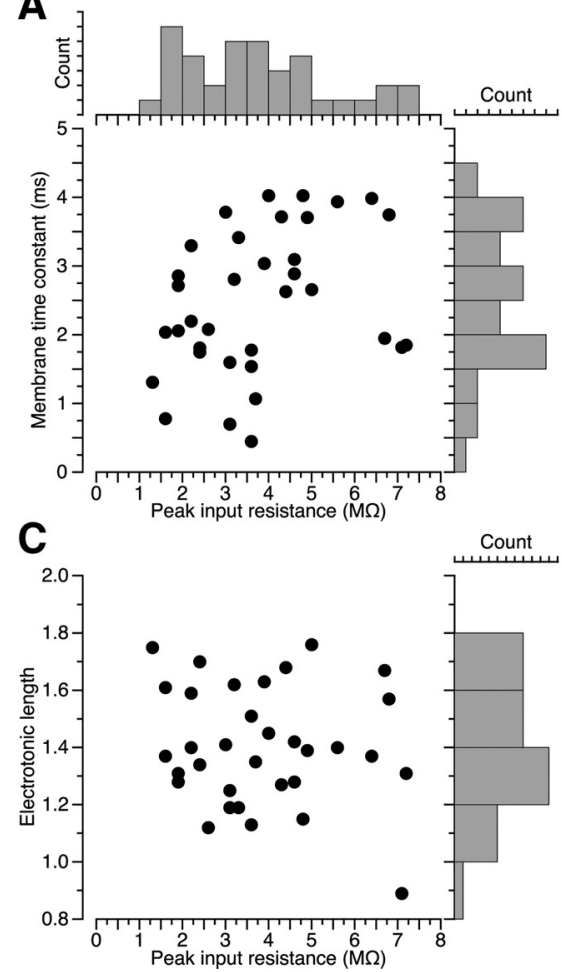

B

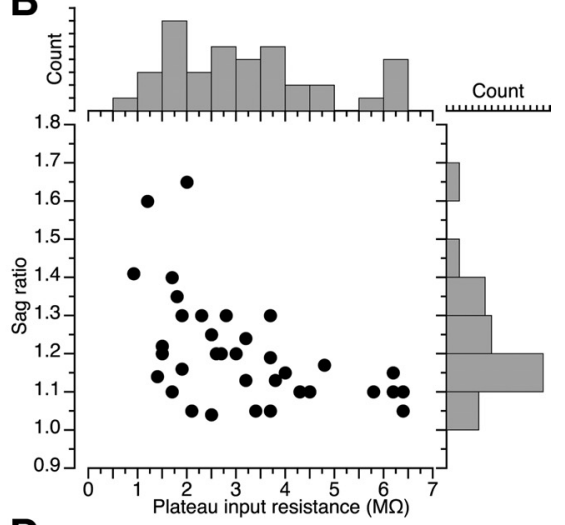

D

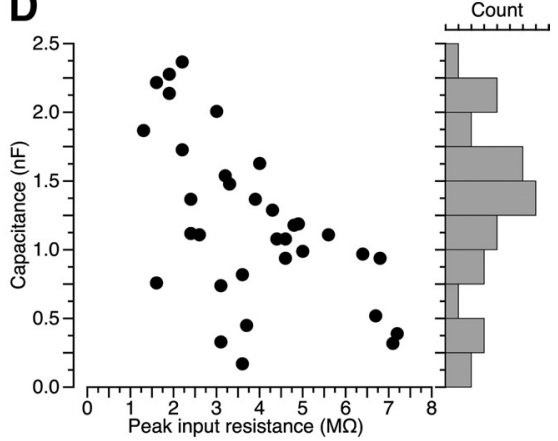

Figure 3. Distributions of subthreshold properties and relations among them. $A$, Plot of the membrane time constant versus the peak input resistance $(r=0.33 ; p=0.055)$ and distribution of these two properties. $\boldsymbol{B}$, Plot of the sag ratio versus the plateau input resistance $(r=-0.48 ; p<0.01)$ and distribution of these two properties. $C$, Distribution of the electrotonic length and plot versus the peak input resistance. $r=-0.13$ (not significant). $D$, Distribution of the total capacitance and plot versus the plateau input resistance. $r=-0.59(p<0.001)$. $r$ is Pearson's correlation coefficient.

Table 1. Summary of the subthreshold properties of mouse motoneurons compared to cats

\begin{tabular}{lll}
\hline & Mice & Cats \\
\hline Peak input resistance $(\mathrm{M} \Omega)$ & $3.7 \pm 1.7(1.3-7.2)^{* * *}$ & $1.4 \pm 0.6(0.5-2.6)^{a}$ \\
& $n=37$ & $n=45$ \\
Plateau input resistance (MS) & $3.1 \pm 1.6(0.9-6.4)^{* * *}$ & $1.1 \pm 0.5(0.4-2.5)^{a}$ \\
& $n=37$ & $n=45$ \\
Sag ratio & $1.2 \pm 0.1(1.0-1.7)$ & $1.4 \pm 0.2(1.0-1.9)^{a}$ \\
& $n=37$ & $n=45$ \\
Membrane time constant & $2.5 \pm 1.0(0.5-4.0)^{* * *}$ & $7.0 \pm 1.5(3.9-14.3)^{b}$ \\
Electrotonic length & $n=35$ & $n=84$ \\
& $1.4 \pm 0.2(0.9-1.8)$ & $1.53 \pm 0.29(1.1-2.5)^{c}$ \\
Cell capacitance (nF) & $n=33$ & $n=25$ \\
& $1.2 \pm 0.6(0.2-2.4)^{* * *}$ & $9.6 \pm 3.9(5.5-14.9)^{d}$ \\
Resonance quality & $n=33$ & $n=95$ \\
& $1.2 \pm 0.2(1.04-1.64)$ & $1.3 \pm 0.2(1.1-1.7)^{a}$ \\
Resonance frequency (Hz) & $n=23$ & $n=39$ \\
& $17 \pm 6(7-30)^{* * *}$ & $11 \pm 3(6-20)^{a}$ \\
& $n=23$ & $n=39$ \\
\hline
\end{tabular}

Values in the cells are mean $\pm S D$, with the range in parentheses, and the number of motoneurons. Asterisks indicate statistically significant differences $\left({ }^{* *} p<0.001\right.$ ) with cat motoneuron data (calculated using a onetailed Student's $t$ test).

${ }^{a}$ Manuel et al. (2007).

${ }^{b}$ Pooled data across physiological types from Zengel et al. (1985).

'Pooled data across physiological types from Burke and ten Bruggencate (1971).

${ }^{d}$ Engelhardt et al. (1989).

spectively. The ratio between these two values (sag ratio) reflected the amount of $I_{h}$ current activated during the pulses. It was equal to 1.3 in this motoneuron. In the whole sample, the peak input resistance varied from 1.3 to $7.2 \mathrm{M} \Omega$ (mean $3.7 \pm 1.7 \mathrm{M} \Omega ; n=$ 37) (Fig. 3A), the plateau input resistance varied from 0.9 to 6.4

$\mathrm{M} \Omega$ (mean $3.1 \pm 1.6 \mathrm{M} \Omega ; n=37$ ) (Fig. $3 B)$, and the sag ratio varied from 1.0 to 1.7 (mean $1.2 \pm 0.1 ; n=37$ ) (Fig. $3 B$ ). The peak input resistances of mouse motoneurons were larger than in cat $[0.6-4.0$ $\mathrm{M} \Omega$ (Gustafsson and Pinter, 1984)] and rat $[0.8-5.1 \mathrm{M} \Omega$ (Bakels and Kernell, 1993; Beaumont and Gardiner, 2002; Cormery et al., 2005; Button et al., 2006)] motoneurons. As shown in Figure $3 A$, there was a tendency for the motoneurons with the largest input resistance to also have the largest membrane time constant $(r=0.33 ; p=0.055)$. There was also a correlation between the sag ratio and the plateau input resistance (Fig. $3 B)(r=$ -0.48 ; $p<0.01$ ) showing that motoneurons with the smallest resistance tended to have the strongest $I_{h}$ current.

We measured the first equalizing time constant as shown in Figure $2 \mathrm{~A}_{2}$ (open circles). It was equal to $0.7 \mathrm{~ms}$ in this motoneuron. This allowed us to estimate its electrotonic length (see Materials and Methods), which was equal to 1.4. In the whole sample, the electrotonic length ranged from 0.9 to 1.8 (mean $1.4 \pm 0.2$; $n=33$ ) (Fig. $3 C$ ), which is similar to the values reported in cat motoneurons ( $\mathrm{Ta}$ ble 1) (Burke and ten Bruggencate, 1971; Gustafsson and Pinter, 1984). The electrotonic length did not depend on the input resistance (Fig. 3C) $(r=-0.13$, not significant), indicating that the electrotonic structure of a motoneuron did not depend on its size.

We calculated the total cell capacitance as explained in Materials and Methods. In the case illustrated in Figure 2, it was equal to $2 \mathrm{nF}$. In the whole sample, the capacitance ranged from 0.2 to $2.4 \mathrm{nF}$ (mean $1.2 \pm 0.6 \mathrm{nF} ; n=33$ ) (Fig. $3 D$ ). This is much smaller than in cat motoneurons (Table 1) [mean $\sim 6 \mathrm{nF}$ (Gustafsson and Pinter, 1984)] and rat motoneurons [mean $\sim 3$ $\mathrm{nF}$ (Cormery et al., 2005)]. The motoneurons with the smallest resistance did have a greater total capacitance (Fig. 3D) $(r=$ $-0.59 ; p<0.001)$, showing that they indeed had a larger membrane area (see Materials and Methods).

\section{Subthreshold resonance occurs at a higher frequency in mouse than in cat motoneurons}

The resonant behavior of mouse motoneurons was investigated in 24 cells. Twenty-three of them showed a resonance at resting membrane potential. In both examples shown in Figure 4, the voltage response to the ZAP current was not constant in amplitude (Fig. $4 A_{1}, B_{1}$ ), and the impedance curve (Fig. $4 A_{2}, B_{2}$ ) displayed a maximum, indicating a resonance. These two examples differ by the resonance frequency $(24 \mathrm{~Hz}$ in the first case and $9 \mathrm{~Hz}$ in the second) and by the quality factor (1.47 in the first example and 1.13 in the second). The resonance in cat spinal motoneurons was found to result from the combined action of the $I_{h}$ current that filters out the low frequencies, and of the passive membrane time constant that filters out the high frequencies (Manuel et al., 2007). The mechanisms are probably the same in mouse motoneurons. As shown in Figure $4 C$, the resonance frequency was correlated to the membrane time constant $(r=-0.68 ; p<$ 
0.001), the resonance frequency decreasing with increasing time constant. The resonance frequency was found to increase with the quality factor (Fig. 4D), which was itself linearly correlated with the sag ratio measured at the same potential $(r=0.68 ; p<0.01 ; n=15)$. This suggests that the sag ratio, the quality factor, and the resonance frequency all depend on the $I_{h}$ conductance (Manuel et al., 2007). Furthermore, hyperpolarizing the one motoneuron that did not show a resonance at resting membrane potential by $13 \mathrm{mV}$ (bias current - $3.5 \mathrm{nA}$ ) elicited a resonant behavior (resonant frequency of $16 \mathrm{~Hz} ; Q=1.2$ ). Again, this suggests that the subthreshold resonance in mouse motoneurons involves the $I_{h}$ current.

For the whole sample, the resonance frequency varied from 7 to $30 \mathrm{~Hz}$ (mean $17 \pm 6 \mathrm{~Hz} ; n=23$ ) (Fig. $4 D$ ), and the quality factor varied from 1.04 to 1.64 (mean $1.2 \pm 0.2 ; n=24$ ) (Fig. $4 D$ ). As shown in Table 1 , the resonance frequency in mouse motoneurons was significantly higher than in cat motoneurons (the resonance has never been investigated in rat motoneurons). This was attributable to the faster membrane time constant of mouse motoneurons. In contrast, the quality factor was the same in mouse and in cat motoneurons (Table 1).

\section{Spike repolarization and AHP are fast in mouse motoneurons}

The characteristics of action potentials elicited by short intracellular depolarizing pulses are displayed in Figure 5, and their mean values and SDs are shown in Table 2. In the example of Figure 5, the spike height was $72 \mathrm{mV}$, its width was $0.30 \mathrm{~ms}$, the amplitude of the AHP was $2.5 \mathrm{mV}$, its time constant was $14 \mathrm{~ms}$, its half-decay time was 10 $\mathrm{ms}$, and its duration was $63 \mathrm{~ms}$. A comparison with data obtained by our group (Manuel et al., 2005; and unpublished data) on 32 lumbar motoneurons of cats (anesthetized with pentobarbital sodium as in the present study) showed that both the kinetics of spike repolarization and the kinetics of the AHP were faster in mouse than in cat motoneurons. On average, the spike width was one-third smaller in mouse motoneurons, the AHP time constant and AHP half-duration were about twice briefer, whereas the AHP duration was one-third shorter. Moreover, the average AHP amplitude was almost twice smaller despite the fact that the input resistance was larger (see above). This strongly suggests that both the kinetics and the AHP conductance recruited after the action potentials are smaller in mouse than in cat lumbar motoneurons. The comparison with rat lumbar motoneurons yielded the same conclusions (AHP half-decay,6.4$25.8 \mathrm{~ms}$; AHP amplitude same order of magnitude as in our sample of mouse motoneurons despite of the smaller input resistance of rat motoneurons) (Bakels and Kernell, 1993; Beaumont and Gardiner, 2002; Button et al., 2006). The smaller AHP conductance in mouse motoneurons might result from the fast repolarization of the spike, which lessens calcium influx and thus reduces the activation of the SK channels (Krnjevic et al., 1978; Zhang and Krnjevic, 1987; Chandler et al., 1994).

Discharge is affected by fast membrane potential oscillations Mouse motoneurons display a phenomenon that has never been observed in cat and rat spinal motoneurons: fast oscillations that can deeply affect the discharge pattern.

Figure 6 shows the responses of a mouse motoneuron to long depolarizing pulses of current (500 ms). The discharge displayed spike-frequency adaptation (Granit et al., 1963; Kernell, 1965), as shown in the frequencygrams of Figure 6. In response to a pulse of $5.3 \mathrm{nA}$ (Fig. $6 A_{1}$ ), the discharge started at a frequency of $125 \mathrm{~Hz}$ and declined rapidly to a firing rate of $22 \pm 6 \mathrm{~Hz}$. However, the discharge was irregular [coefficient of variation (CV) 27\%] after the adaptation period. The magnification on Figure $6 A_{2}$ reveals the presence of fast oscillations (filled arrowheads), which could reach $2 \mathrm{mV}$ in amplitude, in all the interspike intervals. These oscillations appeared after the AHP had fully relaxed and the membrane potential had returned to baseline. They allowed the motoneuron to discharge with an interspike interval longer than the duration of the AHP, but at the expense of an irregular discharge, since spikes were triggered after a variable number of oscillations. In response to a larger pulse (5.7 nA) (Fig. $6 B_{1}$ ), irregularities were still observed in the discharge despite the higher mean frequency $(54 \pm 15 \mathrm{~Hz}$ after the adaptation; CV $28 \%$ ). The enlargement on Figure $6 B_{2}$ shows again the presence 


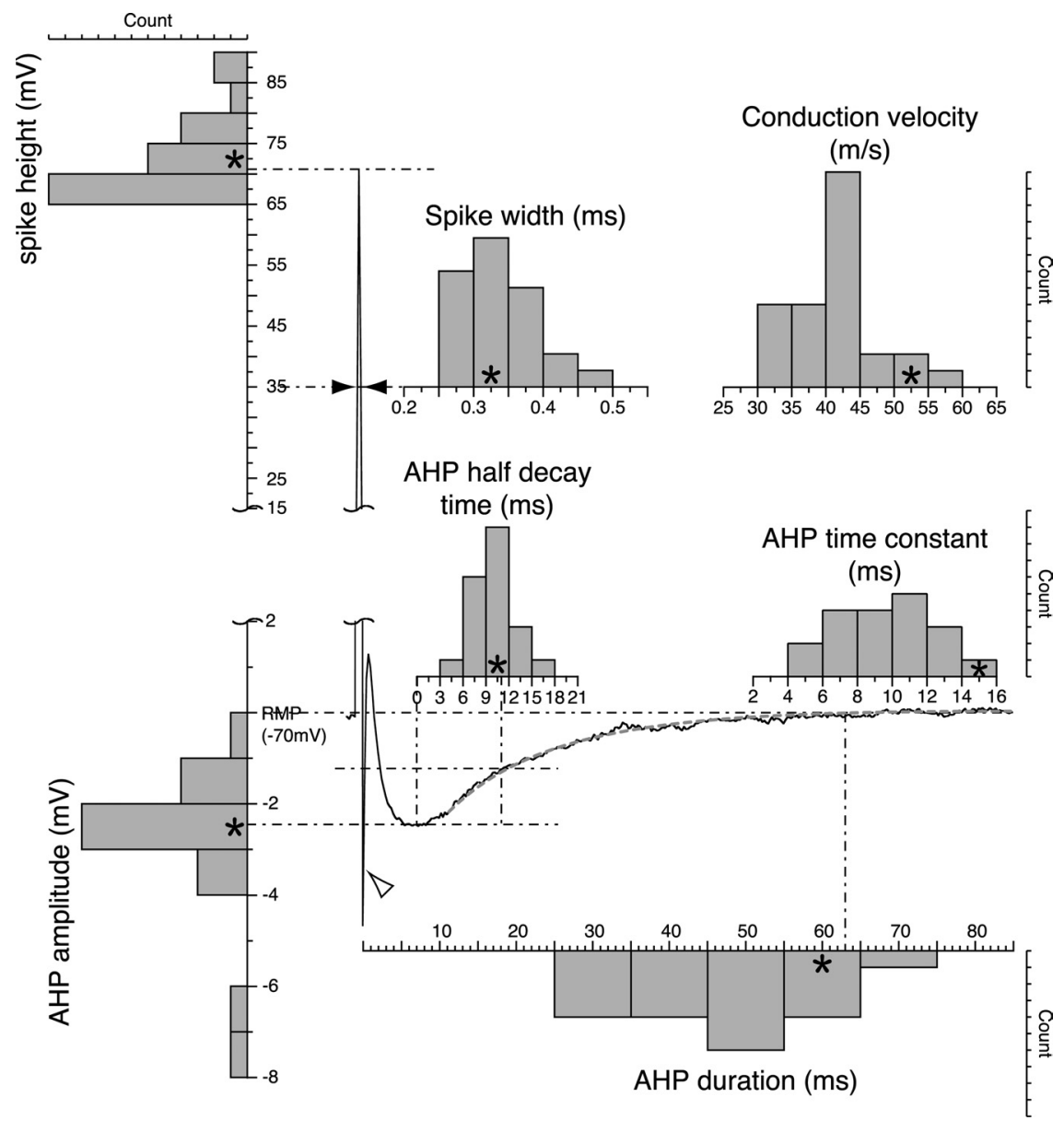

Figure 5. Spike properties in mouse motoneurons. Shown are the characteristics of a typical spike and its AHP. The spike was elicited by a brief depolarizing current pulse $(5 \mathrm{nA}, 0.5 \mathrm{~ms})$. The middle part of the spike has been removed. The lower part of the spike is shown with a larger voltage expansion than the upper part. Note that mouse motoneurons display a strong fast AHP (open arrowhead) that precedes the slower AHP mediated by SK channels. The distributions of the spike height, the spike width, the AHP amplitude, the AHP half-decay time, the AHP time constant, and the AHP duration in our sample of motoneurons are shown. In each of these histograms, an asterisk indicates the bin corresponding to the exemplified spike. Note also that each histogram is aligned with the voltage or the time scales of the illustrated spike. The histogram on the top right side shows the distribution of the axonal conduction velocity. It was computed from the latency of the antidromic action potentials and ranged from 30 to $55 \mathrm{~m} / \mathrm{s}$ $(41 \pm 6 \mathrm{~m} / \mathrm{s} ; n=28)$.

Table 2. Summary of the characteristics of the action potential in mouse and cat motoneurons

\begin{tabular}{lll}
\hline & Mice & Cats \\
\hline Spike height (mV) & $72 \pm 7(65-88)^{* * *}$ & $87 \pm 10(64-111)$ \\
& $n=25$ & $n=32$ \\
Spike width (ms) & $0.30 \pm 0.05(0.25-0.50)^{* * *}$ & $0.45 \pm 0.10(0.35-0.70)$ \\
& $n=25$ & $n=32$ \\
AHP amplitude (mV) & $2.8 \pm 1.7(0.9-7.6)^{* * *}$ & $5.2 \pm 1.7(1.8-9.7)$ \\
& $n=20$ & $n=32$ \\
Time to peak (ms) & $7.3 \pm 2.9(1.4-13.6)^{* * *}$ & $10.5 \pm 3.2(7.3-18.7)$ \\
& $n=20$ & $n=32$ \\
AHP time constant (ms) & $10 \pm 3(6-14)^{* * *}$ & $19 \pm 7(10-41)$ \\
& $n=19$ & $n=32$ \\
AHP half-decay time (ms) & $10.1 \pm 2.4(5.6-15.8)^{* * *}$ & $21.1 \pm 7.1(11.3-42.6)$ \\
& $n=20$ & $n=32$ \\
AHP duration (ms) & $46 \pm 11(26-67)^{* * *}$ & $73 \pm 22(40-141)$ \\
& $n=19$ & $n=32$
\end{tabular}

Values in the cells are mean $\pm S D$, with the range in parentheses, and the number of motoneurons. Asterisks indicate statistically significant differences $\left({ }^{* * *} p<0.001\right)$ with cat motoneuron data (calculated using a one-tailed Student's $t$ test). Cat data are from Manuel et al. (2005) and our unpublished data. of oscillations (filled arrowheads) in some interspike intervals. They delayed the occurrence of the next spike and lowered the firing frequency, again at the expense of a greater firing variability. The oscillations disappeared when the current intensity was increased to $7 \mathrm{nA}$ (Fig. $\left.6 C_{1}\right)$. After adaptation, the stationary discharge was much more regular $(98 \pm 3$ $\mathrm{Hz}$; CV 3\%). In this case, the interspike intervals were fully dominated by the AHP as shown in Figure $6 C_{2}$.

The mean stationary discharge frequency is plotted against the current intensity (see Materials and Methods) in Figure $6 D$. The depolarizing pulses elicited in this motoneuron a sustained discharge for current intensities starting from $5.3 \mathrm{nA}$ (as in Fig. 6A). However, many oscillations were visible in the response, up to a current of $6.5 \mathrm{nA}$. When oscillations were present, the discharge was irregular as indicated by the large SDs. For larger currents, oscillations were no longer present, and every spike was generated at the end of the AHP ramp as in Figure $6 C$. After the initial adaptation, the stationary discharge was very regular (as indicated by the short SD bars in Fig. $6 D$ ), and the mean frequency increased linearly with the injected current. This last region was similar to the classical primary range that has been described extensively in lumbar motoneurons of anesthetized cats and rats [see Powers and Binder (2001) for a review]. By analogy, we propose to call the zone of irregular discharge preceding the primary range, the subprimary range. The gain of the motoneuron can only be meaningfully defined in the linear primary range. The slope of the best linear fit in this range (solid line) yielded a value of $12 \mathrm{~Hz} / \mathrm{nA}$.

The oscillations displayed a clear voltage dependence and appeared in the response to currents at smaller intensities than the current threshold for eliciting a sustained repetitive discharge (i.e., even before the subprimary range). In the example shown in Figure 7, a few spikes appeared at the beginning of each pulse, but the discharge tended to stop rapidly (Fig. $7 C$ ). The traces shown in Figure $7 A_{1}-A_{4}$ are samples of the voltage taken after the cessation of the discharge. Whereas almost no oscillations were present when the potential was held at $-55 \mathrm{mV}$ (Fig. $7 A_{1}$ ), they appeared at $-52 \mathrm{mV}$ (Fig. $7 A_{2}$ ) and increased in size when the membrane potential was depolarized. The voltage threshold for the oscillations was below the voltage threshold for spiking (Fig. 7C). The oscillations were periodic as shown by the autocorrelograms below the records, in which peaks appeared with a period of $8 \mathrm{~ms}$. The periodic character became more and more marked as the voltage increased (Fig. $7 B$ ). The frequency of the oscillations was astonishingly high, $\sim 125 \mathrm{~Hz}$ in this motoneuron, and did not seem to depend on the membrane potential (Fig. $7 B$ ).

We plotted the F-I curve of the motoneurons using a triangular ramp of current, rather than a series of square current pulses 
of increasing intensity, because it took much less time. We first verified on the same motoneuron as in Figure 6 that the same $F$ - $I$ curve was obtained using the "ramp protocol" compared with the "pulse protocol." We started with a very slow ramp $(0.16 \mathrm{nA} / \mathrm{s})$ (Fig. $8 A)$ to be as close as possible to the stationary condition. Once recruited, the motoneuron started to discharge in a very irregular manner and at rates as low as $2-3 \mathrm{~Hz}$. For a current $>4.5 \mathrm{nA}$, the discharge frequency tended to switch between a low and a higher rate as shown by the frequencygram in Figure $8 A_{1}$. The discharge was very hysteretic: the motoneuron was recruited by a current of $3.3 \mathrm{nA}$ but stopped discharging for a current of $5.5 \mathrm{nA}$ on the descending ramp (Fig. $8 A_{4}, F$-I curve). As shown in Figure $8, A_{2}$ and $A_{3}$, oscillations (filled arrowheads) were again responsible for the discharge irregularities. At the end of the ramp (close to Fig. $8 A_{3}$ ), despite the fact that many spikes occurred immediately after the AHP (interspike intervals fully "dominated" by the AHP; open arrowheads), some spikes were preceded by one oscillation, indicating that the current is still within the subprimary range. In this range, the $F$ - $I$ curve is highly nonlinear (Fig. 8 $A_{4}$ ). To reach the primary range, we needed to inject more current. We thus used a faster ramp to obtain the $F$ - I curve within a reasonable time. We injected a current ramp reaching $7.4 \mathrm{nA}$ with a velocity of $1.33 \mathrm{nA} / \mathrm{s}$ (Fig. $8 B$ ). In these conditions, the subprimary range (with fast oscillations and an irregular discharge) (Fig. $8 B_{2}$ ) was rapidly traversed before the primary range was reached. In the primary range, there was no oscillation in the interspike intervals (Fig. $8 B_{3}$ ), the discharge increased linearly, and the gain (measured on the ascending branch) was equal to $13 \mathrm{~Hz} / \mathrm{nA}$ (i.e., close to the gain measured in the stationary conditions with long pulses; see above). In these conditions, the hysteresis of the subprimary range was much less important (Fig. $8 B_{4}$ ) than with the slow ramp (Fig. $8 A_{4}$ ).

We then systematically tested the effect of $0.1-2.5 \mathrm{nA} / \mathrm{s}$ triangular ramps of current in 30 motoneurons. Twenty-two motoneurons displayed a sustained discharge in response to these ramps. In all of them, oscillations accompanied the discharge. They were present in the subprimary range and were repeated in the interspike intervals at a frequency of 100-150 Hz. The oscillations were highly voltage dependent: they appeared a few millivolts below the voltage threshold of the first spike of the ramp and, in the subprimary range, they occurred at the end of the AHP ramp, when the potential approached the voltage threshold for spiking. In 12 motoneurons, a primary range followed the subprimary range (as in Fig. $8 \mathrm{~B}$ ). The primary range started at current intensities $0.2-2.7 \mathrm{nA}(1.0 \pm 0.6 \mathrm{nA} ; n=12)$ above the
$B_{1}$

$\mathrm{C}_{1}$

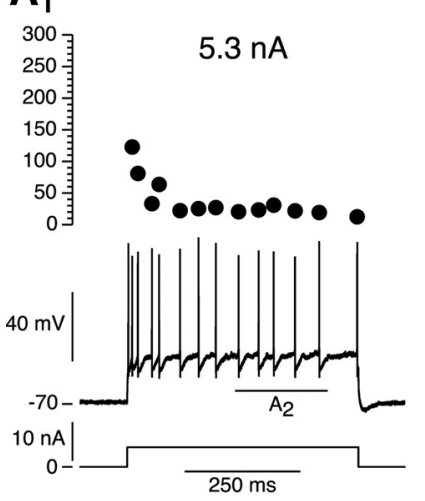

$5.7 \mathrm{nA}$

- $\quad 7.0 \mathrm{nA}$

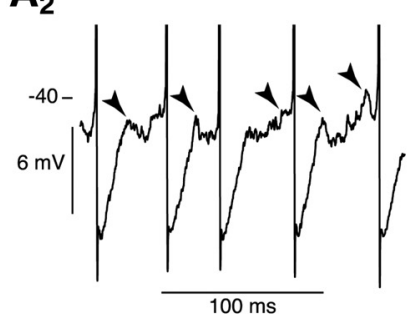

$\mathrm{B}_{2}$
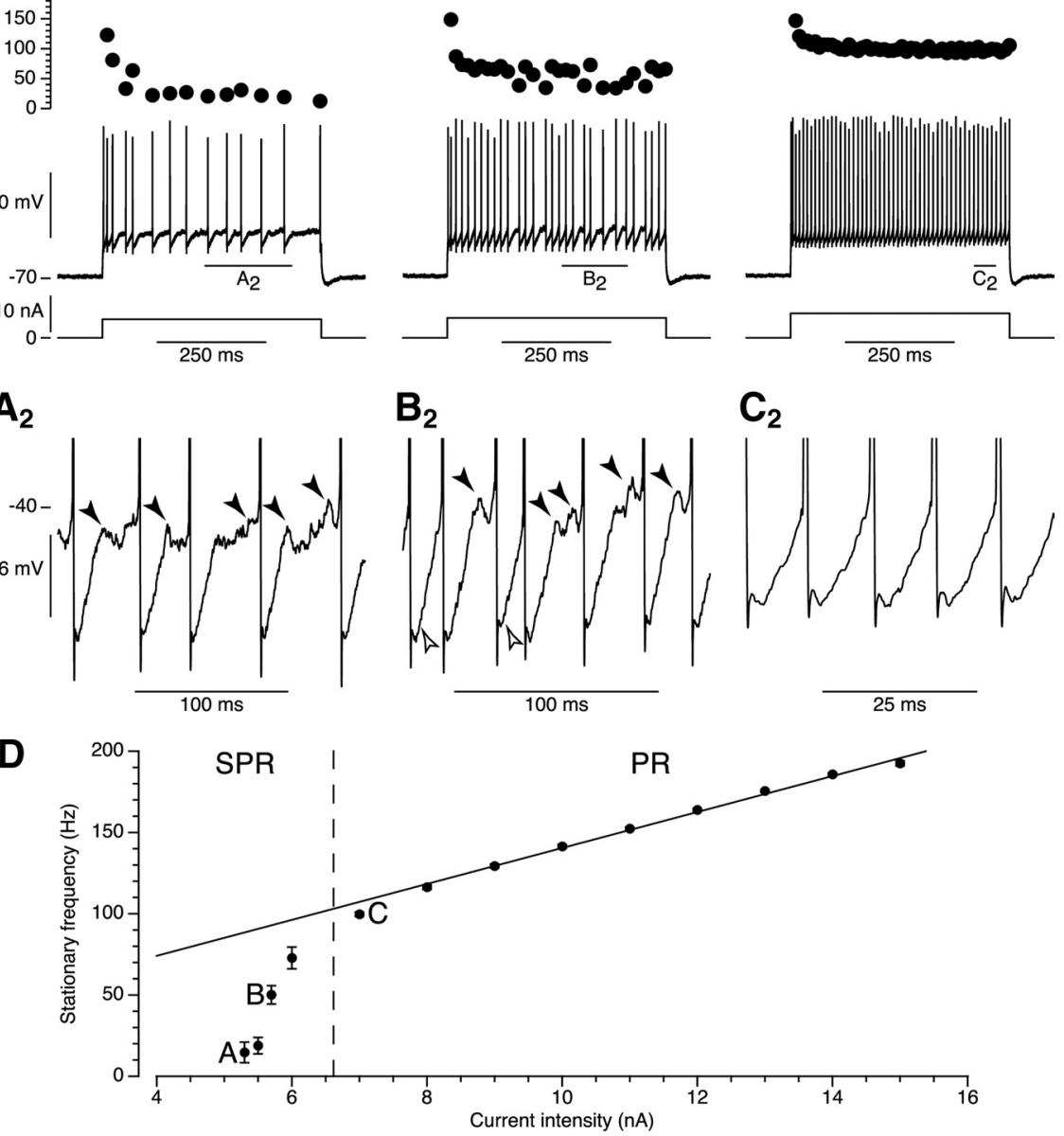

Figure 6. Discharge properties of mouse motoneurons. $\boldsymbol{A}_{\boldsymbol{1}}$, Voltage response (middle trace) of a motoneuron to a $5.3 \mathrm{nA}, 500 \mathrm{~ms}$ square pulse of current (bottom trace). $\boldsymbol{A}_{2}$, Magnification of the region indicated by the horizontal line in $\boldsymbol{A}_{\boldsymbol{1}}$. Filled arrowheads

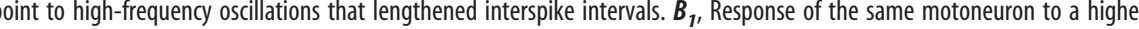
intensity of current (5.7 nA). $\boldsymbol{B}_{2}$, Magnification of the region indicated by the horizontal line in $\boldsymbol{B}_{\mathbf{1}}$. Open arrowheads indicate the AHP, and filled arrowheads point to the fast oscillations that delayed the occurrence of a spike. $\boldsymbol{C}_{1}$, Response of the same motoneuron to an even larger $(7.0 \mathrm{nA})$ current pulse. $\boldsymbol{C}_{2}$, Magnification of the region indicated by the horizontal line in $\boldsymbol{C}_{\mathbf{1}}$. Notice that the time base is shorter than in $\boldsymbol{A}_{\mathbf{2}}$ and $\boldsymbol{B}_{\mathbf{2}}$. $\boldsymbol{D}$, Plot of the stationary discharge versus the very irregular (as shown by the large error bars), and there was no linear relationship between the firing frequency and the current intensity [subprimary range (SPR)]. For currents $>6.6 \mathrm{nA}$, the firing frequency became much more regular (the error bars are $(P R)]$. The slope of the linear regression in the PR (solid line) gives an estimate of the gain of the motoneuron. The responses in $\boldsymbol{A}$ and $\boldsymbol{B}$, where high-frequency oscillations were visible, correspond to a current intensity in the SPR, whereas the response in $\boldsymbol{C}$, where no oscillation was visible, corresponds to the first point in the PR.

recruitment current. The discharge frequency at the onset of the primary range varied from 40 to $70 \mathrm{~Hz}(58 \pm 10 \mathrm{~Hz} ; n=12)$. A hysteresis was present most of the time on the sub-primary range (as in Fig. 8). This hysteresis was clockwise, with offset current higher than onset. We never observed any counterclockwise hysteresis on the primary range as in decerebrate cats (Hounsgaard et al., 1988). This lack might be attributable to a blockade of the nimodipine-sensitive L-type calcium current by the anesthetics (Guertin and Hounsgaard, 1999) or to the low level of neuromodulation of our preparation (Lee and Heckman, 2000). The gain in the primary range varied from 9 to $50 \mathrm{~Hz} / \mathrm{nA}(17 \pm 11$ $\mathrm{Hz} / \mathrm{nA} ; n=12)$. It was larger than in cat motoneurons $(0.7-2.1$ $\mathrm{Hz} / \mathrm{nA}$; mean $1.4 \pm 0.4 \mathrm{~Hz} / \mathrm{nA} ; n=16$ ) (Manuel et al., 2006) than 

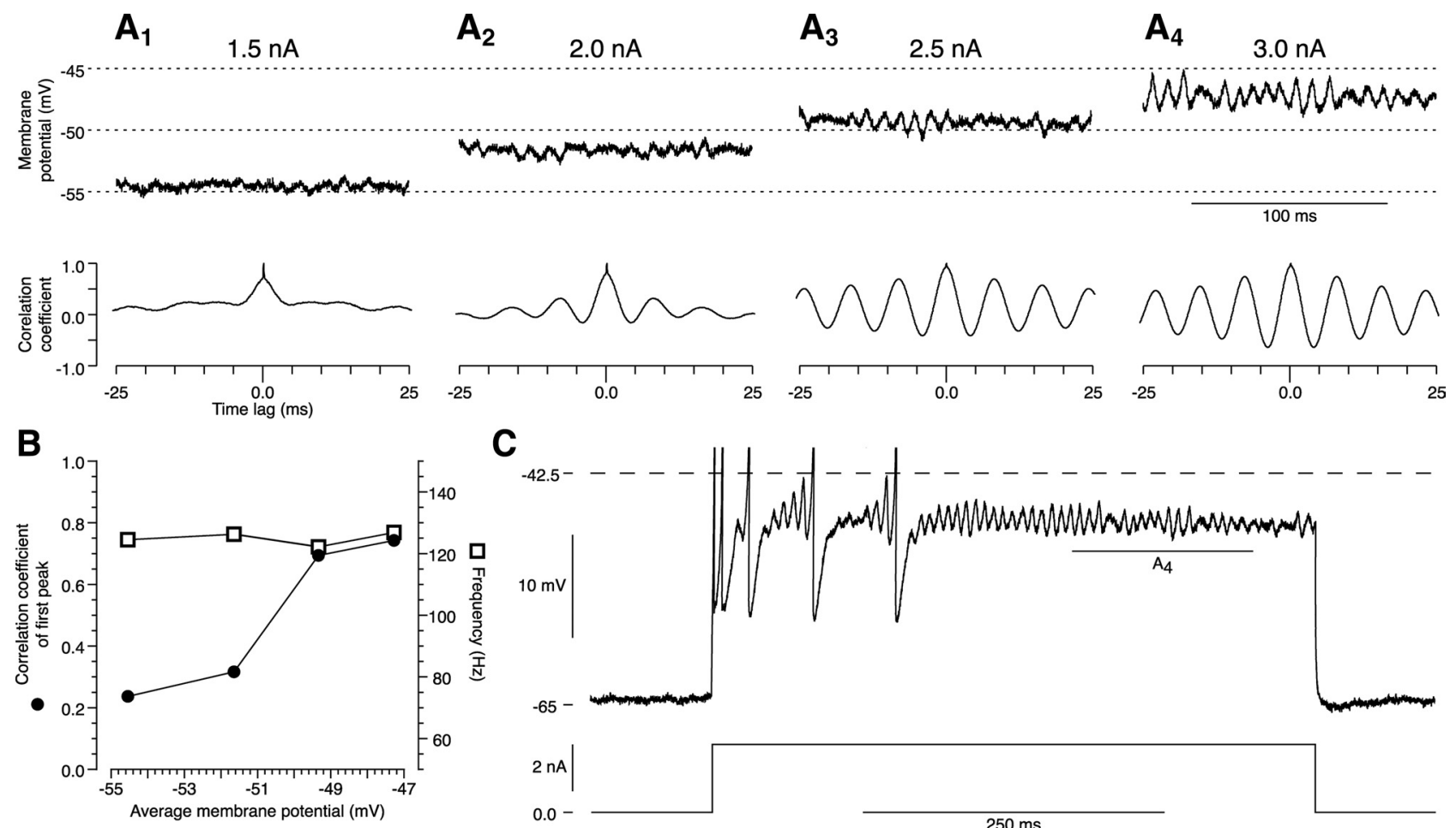

C

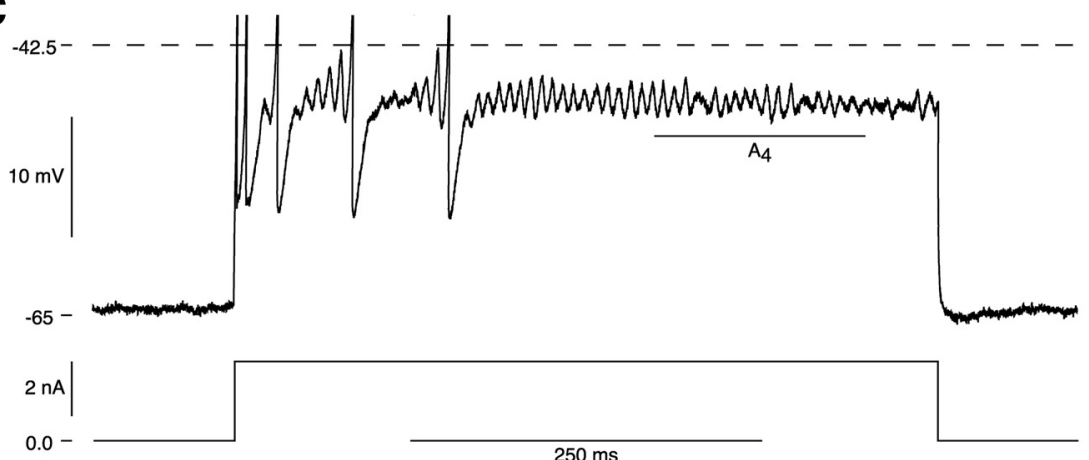

Figure 7. Voltage dependence of the high-frequency oscillations. $A_{1}-A_{4}$, Responses to square pulses of currents (intensity indicated in each panel). The top trace is a sample of the voltage response, and the bottom trace is a sample of the autocorrelogram computed on a period of at least $200 \mathrm{~ms}$ where no spikes were present. When a current of $1.5 \mathrm{nA}$ was injected $\left(\boldsymbol{A}_{1}\right)$, the average voltage of the response was $-55 \mathrm{mV}$, and no oscillations were apparent on the membrane potential. As the injected current was increased and the potential got more depolarized $\left(\boldsymbol{A}_{2}-\boldsymbol{A}_{4}\right)$, oscillations of increasing amplitude appeared. The autocorrelograms show clear periodic components with larger and larger peaks. $\boldsymbol{B}$, Plots of the correlation coefficient and the frequency of the first peak in the autocorrelograms versus the average membrane potential. The correlation coefficient increased with the depolarization of the membrane potential, indicating that the periodic character of the oscillations became more and more marked as the voltage increased. However, the frequency of the oscillations was not voltage dependent. C, Voltage response (top trace; spikes have been truncated) of the motoneuron to a $3.0 \mathrm{nA}$ current pulse (bottom trace). The horizontal dashed line represent the voltage threshold of the last spike. Note that subthreshold oscillations are visible in the intervals between the spikes and that they appear a few millivolts more hyperpolarized than the voltage threshold of the stationary discharge. The autocorrelogram in $A_{4}$ was obtained from the region indicated by the solid line (i.e., when the motoneuron stopped discharging).

in rat motoneurons $(1.3-4.1 \mathrm{~Hz} / \mathrm{nA}$; mean $2.7 \mathrm{~Hz} / \mathrm{nA} ; n=10)$ (Granit et al., 1963). In the remaining 10 motoneurons (which did not differ from the others in terms of input resistance or threshold for spiking), we were not able to reach the primary range although we injected a similar amount of current as in motoneurons where a primary range was observed. The reason why these motoneurons do not display a primary range remains unclear.

\section{Discussion}

Mouse motoneurons were found to have a brief membrane time constant, a fast spike followed by a fast AHP, and high-frequency subthreshold oscillations. The latter made the discharge irregular and were responsible for a subprimary range in the $F-I$ curve. These oscillations and the resulting subprimary range have never been observed in cat and in rat motoneurons.

\section{A smaller geometry, but the same electrotonic length, compared with other species}

The faster time constant of mouse motoneurons indicates that their specific membrane resistivity is smaller than in cat and rat motoneurons. Since many ionic channels are opened at rest (HCN, leak potassium currents, etc.) (McLarnon, 1995), we suggest that their density is higher in the membrane of mouse motoneurons than in cat and rat motoneurons. Although mouse motoneurons have a small specific membrane resistivity, they have a high input resistance. This discrepancy hints at a membrane surface smaller than in other species. Indeed, our estimation of the cell capacitance suggests that the membrane surface of mouse $\alpha$-motoneurons is approximately five to eight times smaller than in cats and two-and-a-half times smaller than in rats. Measuring the dendritic and the somatic surface in threedimensional reconstructed mouse motoneurons would be required to confirm this prediction, but these data are available so far only in neonates (Amendola and Durand, 2008). In adults, we can only compare the size of the soma measured on planar projections. In the study by McHanwell and Biscoe (1981), the equivalent circle diameters of the soma ranged from 19 to $37 \mu \mathrm{m}$ (mean $\sim 26 \mu \mathrm{m} ; 32 \mu \mathrm{m}$ in the motoneuron we labeled in Fig. $1 B$ ). For comparison, in cat motoneurons, soma diameters ranged from 40 to $80 \mu \mathrm{m}$ (mean $\sim 50 \mu \mathrm{m}$ ) (Burke et al., 1977; Ulfhake and Kellerth, 1984; Horcholle-Bossavit et al., 1988), whereas they ranged from 20 to $40 \mu \mathrm{m}$ (mean $30 \mu \mathrm{m}$ ) in rats (Swett et al., 1986; Hashizume et al., 1988; Roy et al., 2007). Finally, Ishihara et al. (2001) showed that the mean somatic diameter of soleus motoneurons was $26 \mu \mathrm{m}$ in mice, $34 \mu \mathrm{m}$ in rats, and $51 \mu \mathrm{m}$ in cats. Altogether, these data indicate that the soma diameter in mouse motoneurons is about twice as small (i.e., membrane area four times smaller) than in cats, and $10-30 \%$ smaller than in rats. The reduction in dendritic membrane area should be even more important to account for by the differences in total membrane area between motoneurons of mice and other species. 
We found that, despite their different geometries, the electrotonic length of motoneurons was similar in mice and cats. Although the formula used in the present study is the best estimator of the electrotonic length, it may overestimate it by up to $20 \%$ in noncompact cells such as motoneurons (Holmes and Rall, 1992). Nevertheless, our results suggest that the electrotonic structure of spinal $\alpha$-motoneurons and the spatial integration of synaptic inputs may be similar across species.

Fast membrane kinetics and

fast-frequency oscillations

In contrast, temporal integration is very different. Because of their small time constant, the resonance frequency of mouse motoneurons is higher than in cat motoneurons, indicating that mouse motoneurons are more responsive to higher-frequency inputs. Moreover, fast responsiveness of the membrane favors the high-frequency oscillations $(100-150 \mathrm{~Hz})$ that are little filtered out. The longer membrane time constant of cat and rat spinal motoneurons might be a reason why they do not display highfrequency oscillations.

Several mechanisms may be hypothesized to explain these oscillations. Gap junctions could elicit them as the result of a collective behavior they induce in a network of electrically coupled neurons (Logan et al., 1996; Kiehn et al., 2000; Placantonakis et al., 2006). However, this hypothesis is unlikely because oscillations appear when depolarizing a single neuron below its spiking threshold. Furthermore, even though gap junctions between motoneurons have been described in neonatal rats (Chang et al., 1999), they tend to disappear with age (Walton and Navarrete, 1991). We also considered the possibility that these fast oscillations are synaptic events coming from a recurrent network. However, the oscillations arose before the very first spike on a current ramp (data not shown). Moreover, the kinetics of the oscillations were probably too fast for synaptic events. For these reasons, we believe high-frequency oscillations in mouse motoneurons are an intrinsic phenomenon.

The fast oscillations are not caused by the subthreshold membrane resonance as in pyramidal cells of the guinea pig frontal cortex (Gutfreund et al., 1995). The subthreshold resonance frequency $(7-30 \mathrm{~Hz})$ seen in mouse motoneurons is indeed too low to account for the high frequencies of oscillations. Furthermore, the oscillations are not present at the resting potential and
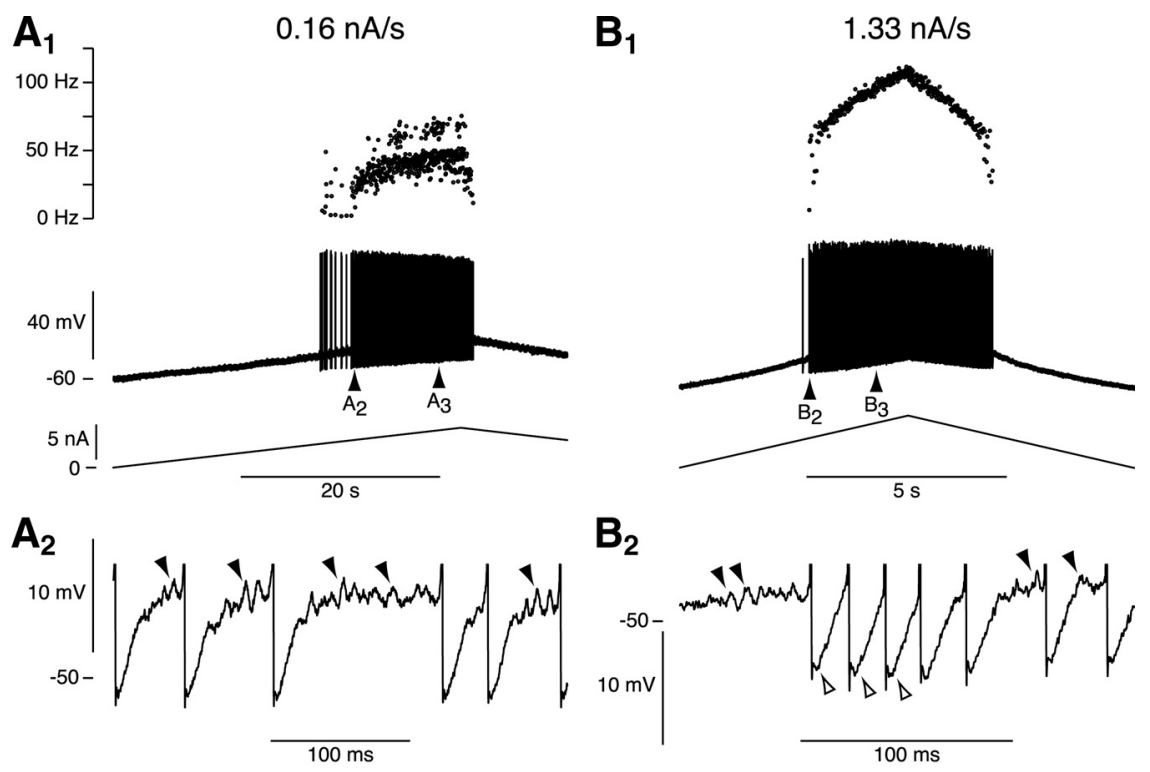

$\mathbf{A}_{3}$

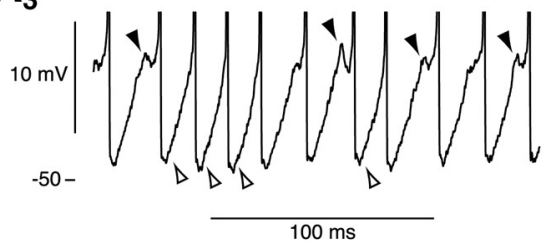

$\mathbf{A}_{4}$

$\mathrm{B}_{3}$

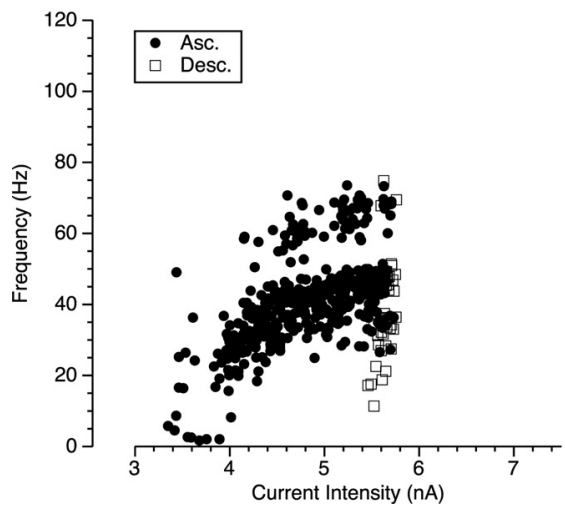

$\mathrm{B}_{4}$
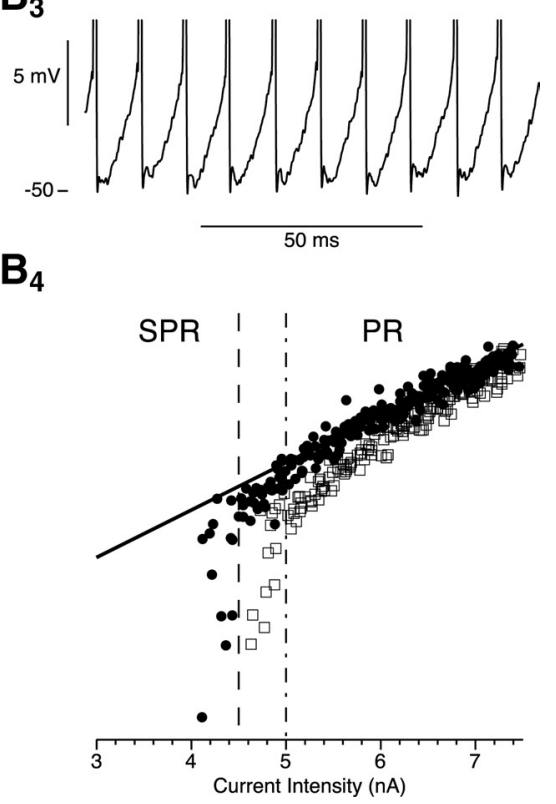

Figure 8. Discharge properties in response to current ramps. $A$, Response of the motoneuron shown in Figure 6 to a slow $(0.16$ $\mathrm{nA} / \mathrm{s}$ ) current ramp. $A_{1}$, Voltage response (middle trace), instantaneous firing frequency (top plot), and slow current ramp (bottom trace). Areas of interest indicated by the filled arrowheads have been magnified in $\boldsymbol{A}_{2}$ and $\boldsymbol{A}_{3} . \boldsymbol{A}_{2}$, Spikes have been truncated. Filled arrowheads point to high-frequency oscillations. $A_{3}$, Open arrowheads indicate interspike intervals presenting no visible oscillations, and filled arrowheads point to high-frequency oscillations. $A_{4}$, Plot of the instantaneous firing frequency versus the intensity of the injected current for this particular ramp. Note the very irregular firing and a frequency generally $>50 \mathrm{~Hz}$. It was impossible to define a linear region in which to measure the slope. Note also that the discharge is very asymmetrical between the ascending branch of the ramp (Asc.; black dots) and the descending phase (Desc.; open squares). $\boldsymbol{B}$, Response of the same motoneuron to a faster current ramp $(1.33 \mathrm{nA} / \mathrm{s})$. $\boldsymbol{B}_{1}$, Same organization as in $\boldsymbol{A}_{1}$. Areas of interest indicated by the arrowheads have been magnified in $\boldsymbol{B}_{2}$ and $\boldsymbol{B}_{3} \cdot \boldsymbol{B}_{2}$, This region corresponded to the very beginning of the discharge, and high-frequency oscillations preceded some of the spikes (filled arrowheads), whereas some interspike intervals were undisturbed (open arrowheads), creating an irregular spiking with long and short interspike intervals. $\boldsymbol{B}_{3}$, Magnification of the region indicated by the corresponding arrow in $\boldsymbol{B}_{1} \cdot \boldsymbol{B}_{4^{\prime}}$ Plot of the instantaneous firing frequency versus the intensity of the injected current for this particular ramp. Contrarily to the situation in $A_{4}$, clear linear region is visible for currents $>4.5 \mathrm{nA}$ [primary range (PR)], whereas the firing is very irregular for lower current intensities [subprimary range (SPR)]. The gain of the $F-I$ curve $(13 \mathrm{~Hz} / \mathrm{nA})$ can be estimated by the slope of the linear regression (straight line) of the PR. Note that the firing frequency reached a much higher level $(\sim 110 \mathrm{~Hz})$ than in $A_{4}$. Note also that although the discharge was more symmetrical that in $A_{4}$, a clockwise hysteresis was still present. The transition between the PR and the SPR occurs for lower current on the ascending branch (dashed vertical line) than on the descending branch (dashed-dotted vertical line). 
appear when depolarizing the neuron in sharp contrast with the resonance. Given the high frequency of the oscillations in mouse motoneurons, we may speculate that they are attributable to fast activating currents. A competition between currents involved in the spiking, namely a fast sodium current (that depolarizes the neuron) and a fast activating potassium current (that tends to repolarize it), might be responsible for the fast oscillations. A similar mechanism was suggested to account for subthreshold oscillations in stellate cells in the rat medial entorhinal cortex (Alonso and Klink, 1993) or in neurons of the layer IV of the frontal cortex (Llinas et al., 1991). The spike of mouse motoneuron is particularly brief, suggesting that the transient sodium current and the delayed-rectifier potassium current are very rapidly activated. In addition, the A-potassium current might also be involved since it activates and inactivates in voltage ranges close to the sodium current (Safronov and Vogel, 1995).

\section{Function of the fast-frequency subthreshold oscillations}

The discharge properties of motoneurons have to match with the mechanical properties of their motor units (Kernell, 2006), in particular with their contraction time, which is faster in mice than in cats and in rats. In a fast contracting muscle, the extensor digitorum longus, the contraction time of mouse motor units varies from 4 to $12 \mathrm{~ms}$ (mean $\sim 9 \mathrm{~ms}$ ) (Bateson and Parry, 1983), whereas in a slow contracting muscle, the soleus, it ranges from 7 to $37 \mathrm{~ms}$ (mean $17 \mathrm{~ms}$ ) (Lewis et al., 1982). For comparison, the contraction time of the fast contracting motor units in the cat gastrocnemius ranges from 16 to $30 \mathrm{~ms}$, whereas their tetanic fusion frequency varies from 52 to $117 \mathrm{~Hz}$ (Burke, 1967). In the same muscles, the corresponding values for the slow contracting motor units are $40-87 \mathrm{~ms}$ and $16-48 \mathrm{~Hz}$, respectively. In view of the very short contraction time of mouse motor units in fast muscles, it is likely that the tetanic fusion frequencies of mouse motor units often exceed $150 \mathrm{~Hz}$. These high discharge frequencies can be reached (Fig. 6D) because of the high gain of mouse motoneurons. The shorter AHP time constant combined with a smaller AHP conductance (see Results) explain why the gain of mouse motoneurons is larger than in cat and rat. Indeed, the gain in the primary range is inversely proportional to the product of the AHP time constant and conductance (Bakels and Kernell, 1993; Meunier and Borejsza, 2005) [see Manuel et al. (2006) for an experimental demonstration].

The primary range started at frequencies between 40 and 70 $\mathrm{Hz}$. This means that most motor units will already develop an unfused tetanus at the onset of the primary range. To produce less force, it is necessary to reduce the firing frequency. This cannot be achieved by the AHP alone. Indeed, if the primary range extended down to the recruitment current, motoneurons would start to fire at $30-65 \mathrm{~Hz}$. The subprimary range created by the fastfrequency oscillations allows motoneurons to fire at much lower frequencies (as low as a few hertz) when they are recruited and until the synaptic inputs are strong enough to bring them to the primary range. Human motoneurons are also able to fire at rates as low as $4 \mathrm{~Hz}$ during voluntary weak contractions (i.e., with an interspike interval longer than the estimated duration of the AHP (Kudina, 1999; Matthews, 1999). This low-frequency firing range was also called subprimary range. However, this low-frequency firing in human motoneurons is thought to be attributable to spikes triggered randomly by synaptic events after the AHP has fully relaxed, instead of fast subthreshold oscillations.

We propose that the function of sub-threshold oscillations in mouse motoneurons is to enable the motor units to produce small forces by lowering the firing frequency. However, this is at the expense of an irregular discharge. It remains to understand how a muscle can then produce calibrated forces despite of the irregular firing of its individual motor units.

\section{References}

Alonso A, Klink R (1993) Differential electroresponsiveness of stellate and pyramidal-like cells of medial entorhinal cortex layer II. J Neurophysiol 70:128-143.

Alstermark B, Ogawa J (2004) In vivo recordings of bulbospinal excitation in adult mouse forelimb motoneurons. J Neurophysiol 92:1958-1962.

Amendola J, Durand J (2008) Morphological differences between wild-type and transgenic superoxide dismutase 1 lumbar motoneurons in postnatal mice. J Comp Neurol 511:329-341.

Bakels R, Kernell D (1993) Matching between motoneurone and muscle unit properties in rat medial gastrocnemius. J Physiol 463:307-324.

Bateson DS, Parry DJ (1983) Motor units in a fast-twitch muscle of normal and dystrophic mice. J Physiol 345:515-523.

Beaumont E, Gardiner P (2002) Effects of daily spontaneous running on the electrophysiological properties of hindlimb motoneurones in rats. J Physiol 540:129-138.

Bories C, Amendola J, Lamotte d'Incamps B, Durand J (2007) Early electrophysiological abnormalities in lumbar motoneurons in a transgenic mouse model of amyotrophic lateral sclerosis. Eur J Neurosci 25:451-459.

Brizzi L, Meunier C, Zytnicki D, Donnet M, Hansel D, Lamotte d'Incamps B, Van Vreeswijk C (2004) How shunting inhibition affects the discharge of lumbar motoneurones: a dynamic clamp study in anaesthetized cats. J Physiol 558:671-683.

Burke RE (1967) Motor unit types of cat triceps surae muscle. J Physiol 193:141-160.

Burke RE, ten Bruggencate G (1971) Electrotonic characteristics of alpha motoneurones of varying size. J Physiol 212:120.

Burke RE, Strick PL, Kanda K, Kim CC, Walmsley B (1977) Anatomy of medial gastrocnemius and soleus motor nuclei in cat spinal cord. J Neurophysiol 40:667-680.

Button DC, Gardiner K, Marqueste T, Gardiner PF (2006) Frequencycurrent relationships of rat hindlimb alpha-motoneurones. J Physiol 573:663-677.

Chandler SH, Hsaio CF, Inoue T, Goldberg LJ (1994) Electrophysiological properties of guinea pig trigeminal motoneurons recorded in vitro. J Neurophysiol 71:129-145.

Chang Q, Gonzalez M, Pinter MJ, Balice-Gordon RJ (1999) Gap junctional coupling and patterns of connexin expression among neonatal rat lumbar spinal motor neurons. J Neurosci 19:10813-10828.

Cormery B, Beaumont E, Csukly K, Gardiner P (2005) Hindlimb unweighting for 2 weeks alters physiological properties of rat hindlimb motoneurones. J Physiol 568:841-850.

Engelhardt JK, Morales FR, Yamuy J, Chase MH (1989) Cable properties of spinal cord motoneurons in adult and aged cats. J Neurophysiol 61:194-201.

Frugier T, Tiziano FD, Cifuentes-Diaz C, Miniou P, Roblot N, Dierich A, Le Meur M, Melki J (2000) Nuclear targeting defect of SMN lacking the C-terminus in a mouse model of spinal muscular atrophy. Hum $\mathrm{Mol}$ Genet 9:849-858.

Granit R, Kernell D, Shortess GK (1963) Quantitative aspects of repetitive firing of mammalian motoneurones, caused by injected currents. J Physiol 168:911-931.

Guertin PA, Hounsgaard J (1999) Non-volatile general anaesthetics reduce spinal activity by suppressing plateau potentials. Neuroscience 88:353-358.

Gurney ME, Pu H, Chiu AY, Dal Canto MC, Polchow CY, Alexander DD, Caliendo J, Hentati A, Kwon YW, Deng HX, Chen W, Zhai P, Sufit RL, Siddique $\mathrm{T}$ (1994) Motor neuron degeneration in mice that express a human Cu,Zn superoxide dismutase mutation. Science 264:1772-1775.

Gustafsson B, Pinter MJ (1984) Relations among passive electrical properties of lumbar alpha-motoneurones of the cat. J Physiol 356:401-431.

Gutfreund Y, Yarom Y, Segev I (1995) Subthreshold oscillations and resonant frequency in guinea-pig cortical neurons: physiology and modelling. J Physiol 483:621-640.

Hashizume K, Kanda K, Burke RE (1988) Medial gastrocnemius motor nucleus in the rat: age-related changes in the number and size of motoneurons. J Comp Neurol 269:425-430. 
Holmes WR, Rall W (1992) Electrotonic length estimates in neurons with dendritic tapering or somatic shunt. J Neurophysiol 68:1421-1437.

Horcholle-Bossavit G, Jami L, Thiesson D, Zytnicki D (1988) Motor nuclei of peroneal muscles in the cat spinal cord. J Comp Neurol 277:430-440.

Hounsgaard J, Hultborn H, Jespersen B, Kiehn O (1988) Bistability of alpha-motoneurones in the decerebrate cat and in the acute spinal cat after intravenous 5-hydroxytryptophan. J Physiol 405:345-367.

Hsieh-Li HM, Chang JG, Jong YJ, Wu MH, Wang NM, Tsai CH, Li H (2000) A mouse model for spinal muscular atrophy. Nat Genet 24:66-70.

Huizar P, Kuno M, Miyata Y (1975) Electrophysiological properties of spinal motoneurones of normal and dystrophic mice. J Physiol 248:231-246.

Hutcheon B, Yarom Y (2000) Resonance, oscillation and the intrinsic frequency preferences of neurons. Trends Neurosci 23:216-222.

Ishihara A, Ohira Y, Tanaka M, Nishikawa W, Ishioka N, Higashibata A, Izumi R, Shimazu T, Ibata Y (2001) Cell body size and succinate dehydrogenase activity of spinal motoneurons innervating the soleus muscle in mice, rats, and cats. Neurochem Res 26:1301-1304.

Kernell D (1965) The limits of firing frequency in cat lumbosacral motoneurones possessing different time course of afterhyperpolarization. Acta Physiol Scand 56:87-100.

Kernell D (2006) The motoneurone and its muscle fibers. Oxford: Oxford UP.

Kiehn O, Kjaerulff O, Tresch MC, Harris-Warrick RM (2000) Contributions of intrinsic motor neuron properties to the production of rhythmic motor output in the mammalian spinal cord. Brain Res Bull 53:649-659.

Krnjevic K, Puil E, Werman R (1978) EGTA and motoneuronal afterpotentials. J Physiol 275:199-223.

Kudina LP (1999) Analysis of firing behaviour of human motoneurones within "subprimary range." J Physiol Paris 93:115-123.

Kuo JJ, Siddique T, Fu R, Heckman CJ (2005) Increased persistent $\mathrm{Na}(+)$ current and its effect on excitability in motoneurones cultured from mutant SOD1 mice. J Physiol 563:843-854.

Lee RH, Heckman CJ (2000) Adjustable amplification of synaptic input in the dendrites of spinal motoneurons in vivo. J Neurosci 20:6734-6740.

Lewis DM, Parry DJ, Rowlerson A (1982) Isometric contractions of motor units and immunohistochemistry of mouse soleus muscle. J Physiol 325:393-401.

Llinas RR, Grace AA, Yarom Y (1991) In vitro neurons in mammalian cortical layer 4 exhibit intrinsic oscillatory activity in the $10-$ to $50-\mathrm{Hz}$ frequency range. Proc Natl Acad Sci U S A 88:897-901.

Logan SD, Pickering AE, Gibson IC, Nolan MF, Spanswick D (1996) Electrotonic coupling between rat sympathetic preganglionic neurones in vitro. J Physiol 495:491-502.

Manuel M, Meunier C, Donnet M, Zytnicki D (2005) How much afterhyperpolarization conductance is recruited by an action potential? A dynamic-clamp study in cat lumbar motoneurons. J Neurosci 25: 8917-8923.

Manuel M, Meunier C, Donnet M, Zytnicki D (2006) The afterhyperpolarization conductance exerts the same control over the gain and variability of motoneurone firing in anaesthetized cats. J Physiol 576:873-886.

Manuel M, Meunier C, Donnet M, Zytnicki D (2007) Resonant or not, two amplification modes of proprioceptive inputs by persistent inward currents in spinal motoneurons. J Neurosci 27:12977-12988.

Matthews PB (1999) Properties of human motoneurones and their synaptic noise deduced from motor unit recordings with the aid of computer modelling. J Physiol Paris 93:135-145.

McHanwell S, Biscoe TJ (1981) The sizes of motoneurons supplying hindlimb muscles in the mouse. Proc R Soc Lond B Biol Sci 213:201-216.

McLarnon JG (1995) Potassium currents in motoneurones. Prog Neurobiol 47:513-531.

Meehan CF, Sukiasyan N, Chakrabarty S, Hulton H, Nielsen JB (2008) Intracellular recording from identified lumbar motoneurones of the adult mouse recorded in vivo. Soc Neurosci Abstr 34:758/MM31.

Meunier C, Borejsza K (2005) How membrane properties shape the discharge of motoneurons: a detailed analytical study. Neural Comput 17:2383-2420.

Monani UR, Sendtner M, Coovert DD, Parsons DW, Andreassi C, Le TT, Jablonka S, Schrank B, Rossoll W, Prior TW, Morris GE, Burghes AH (2000) The human centromeric survival motor neuron gene (SMN2) rescues embryonic lethality in $\operatorname{Smn}(-/-)$ mice and results in a mouse with spinal muscular atrophy. Hum Mol Genet 9:333-339.

Pape HC (1996) Queer current and pacemaker: the hyperpolarizationactivated cation current in neurons. Annu Rev Physiol 58:299-327.

Placantonakis DG, Bukovsky AA, Aicher SA, Kiem HP, Welsh JP (2006) Continuous electrical oscillations emerge from a coupled network: a study of the inferior olive using lentiviral knockdown of connexin36. J Neurosci 26:5008-5016.

Powers RK, Binder MD (2001) Input-output functions of mammalian motoneurons. Rev Physiol Biochem Pharmacol 143:137-263.

Rall W (1969) Time constants and electrotonic length of membrane cylinders and neurons. Biophys J 9:1483-1508.

Rall W, Burke RE, Holmes WR, Jack JJ, Redman SJ, Segev I (1992) Matching dendritic neuron models to experimental data. Physiol Rev 72:S159-S186.

Roy RR, Matsumoto A, Zhong H, Ishihara A, Edgerton VR (2007) Rat alpha- and gamma-motoneuron soma size and succinate dehydrogenase activity are independent of neuromuscular activity level. Muscle Nerve 36:234-241.

Safronov BV, Vogel W (1995) Single voltage-activated Na+ and K+ channels in the somata of rat motoneurones. J Physiol 487:91-106.

Swett JE, Wikholm RP, Blanks RH, Swett AL, Conley LC (1986) Motoneurons of the rat sciatic nerve. Exp Neurol 93:227-252.

Ulfhake B, Kellerth JO (1984) Electrophysiological and morphological measurements in cat gastrocnemius and soleus alpha-motoneurones. Brain Res 307:167-179.

van Zundert B, Peuscher MH, Hynynen M, Chen A, Neve RL, Brown RH, Jr., Constantine-Paton M, Bellingham MC (2008) Neonatal neuronal circuitry shows hyperexcitable disturbance in a mouse model of the adultonset neurodegenerative disease amyotrophic lateral sclerosis. J Neurosci 28:10864-10874.

Walton KD, Navarrete R (1991) Postnatal changes in motoneurone electrotonic coupling studied in the in vitro rat lumbar spinal cord. J Physiol 433:283-305.

Zengel JE, Reid SA, Sypert GW, Munson JB (1985) Membrane electrical properties and prediction of motor-unit type of medial gastrocnemius motoneurons in the cat. J Neurophysiol 53:1323-1344.

Zhang L, Krnjevic K (1987) Apamin depresses selectively the afterhyperpolarization of cat spinal motoneurons. Neurosci Lett 74:58-62. 